Virginia Commonwealth University

VCU Scholars Compass

Social Work Publications

School of Social Work

2012

\title{
Intimate Partner Violence and Alcohol Problems in Interethnic and Intra-ethnic Couples
}

Karen G. Chartier

Virginia Commonwealth University, kgchartier@vcu.edu

Raul Caetano

University of Texas at Dallas

Follow this and additional works at: http://scholarscompass.vcu.edu/socialwork_pubs

Part of the Race and Ethnicity Commons, Social Work Commons, and the Substance Abuse and Addiction Commons

(C) The Author(s) 2012. This is the author's version of a work that was accepted for publication in J Interpers Violence. 2012 Jun; 27(9): 1780-1801. The final publication is available at http://dx.doi.org/10.1177/0886260511430392.

\section{Downloaded from}

http://scholarscompass.vcu.edu/socialwork_pubs/7

This Article is brought to you for free and open access by the School of Social Work at VCU Scholars Compass. It has been accepted for inclusion in Social Work Publications by an authorized administrator of VCU Scholars Compass. For more information, please contact libcompass@vcu.edu. 


\title{
Intimate Partner Violence and Alcohol Problems in Interethnic and Intra-ethnic Couples
}

\author{
Karen G. Chartier ${ }^{1}$ and Raul Caetano ${ }^{1}$ \\ ${ }^{1}$ University of Texas School of Public Health, Dallas Regional Campus
}

Abstract

Despite the growing number of interethnic marriages in the U.S., few studies have examined intimate partner violence (IPV) in interethnic couples. This article examined past-year occurrences of IPV across interethnic and intra-ethnic couples and tested correlates of IPV specifically in interethnic couples. Data were from a national survey of couples 18 years of age and older from the 48 contiguous states. Interethnic couples $(n=116)$ included partners from different ethnic backgrounds, including black-white, Hispanic-white, and black-Hispanic couples. White ( $n=$ $555)$, black $(n=358)$, and Hispanic $(n=527)$ intra-ethnic couples included partners with the same ethnicity. Data analyses were prevalence rates and logistic regressions. The analyses showed that interethnic couples were comparatively younger and had shorter relationships than intra-ethnic white, black, and Hispanic couples. Male partners in interethnic couples had higher rates of binge drinking and alcohol problems compared to male partners in intra-ethnic couples. Past year prevalence rates for any occurrence of IPV and acts of severe IPV were higher for interethnic couples relative to intra-ethnic couples. Most occurrences of IPV for interethnic couples were mutual. Factors predicting IPV among interethnic couples included marital status, couples' age, male alcohol problems, and female impulsivity. Mounting evidence points to interethnic couples as a high risk group for IPV. Interethnic couples may be at greater risk for IPV because of their younger age, binge drinking and alcohol problems. Future research could build on this study by examining cohort effects and regional differences in IPV for interethnic couples, and the risk for IPV across interethnic couples of different ethnic compositions.

\section{Keywords}

interethnic couples; intimate partner violence; alcohol problems; binge drinking

\section{Introduction}

Over the 2 decades from 1980 to 2000, the percentage of interethnic married couples in the U.S. doubled from 3.2\% to 6.8\% (Passel, Wang, \& Taylor, 2010). National attitudes about interethnic marriage also changed during this time period. In 2002, $65 \%$ of the U.S. population approved of interethnic marriage compared to $43 \%$ in 1983 (Carroll, 2007). Younger Americans are most likely to approve of interethnic relationships and to marry someone from a different ethnic group. In 2008, $14.6 \%$ of new marriages in the U.S. were between partners of a different ethnicity; $9 \%$ of whites, $16 \%$ of blacks, and $26 \%$ of

Corresponding Author: Karen G. Chartier, PhD, 6011 Harry Hines Boulevard, V8.112 Dallas, TX 75390-9128 Phone:

214-648-6574 Fax: 214-648-1081 Karen.Chartier@UTSouthwestern.edu.

Declaration of Conflicting Interests

The authors declare that they have no conflicts of interests with respect to their authorship or the publication of this article. 
Hispanics married someone with a different ethnic background than their own (Passel et al., 2010).

Despite these growing trends in interethnic marriage, few studies on intimate partner violence (IPV) have examined the rates and the factors associated with IPV in interethnic couples. Studies examining ethnic group differences in IPV have instead focused on couples in which both partners share the same ethnic background (e.g., white, black and Hispanic intra-ethnic couples). Hispanic couples and, more particularly, black couples are reported to have higher risks for IPV, including unidirectional male-to-female intimate partner violence (MFVP) and female-to-male partner violence (FMPV), relative to white couples (Caetano, Cunradi, Clark, \& Schafer, 2000; Cazenave \& Straus, 1990; Hattery, 2009; Straus \& Smith, 1990). Black and Hispanic couples also have higher rates than whites of severe acts of IPV (Caetano, Ramisetty-Mikler, \& Field, 2005; Cazenave \& Straus, 1990; Cunradi, Caetano, \& Schafer, 2002b; Straus \& Smith, 1990). Black couples are more likely than white and Hispanic couples to engage in mutual partner violence (i.e., bidirectional partner violence) (Caetano et al., 2005), although similar risks for mutual IPV have also been reported across ethnic groups (Field \& Caetano, 2004).

There is some evidence to suggest that interethnic households, like intra-ethnic black and Hispanic households, are at elevated risk for IPV. U.S. incidence rates of spouse homicide from 1976 to 1985, a lethal form of IPV, were 7.7 times higher in black-white interethnic marriages compared to black and white intra-ethnic marriages (Mercy \& Saltzman, 1989). Black men in interethnic relationships are more likely than black men in intra-ethnic relationships to perpetrate acts of partner violence (Hattery, 2009). Fusco (2010) used county police reports to examine interethnic and intra-ethnic couple differences in IPV for a more diverse community sample of whites, blacks, Asians, and Hispanics. Interethnic couples were more likely than intra-ethnic minority and white couples to have a prior history of IPV and to experience mutual IPV in which both partners were determined by police to be equally involved in perpetrating violence. Victims of IPV in interethnic couples were also at greater risk of being injured during the violence when compared to intra-ethnic couples. This may suggest that interethnic couples engage in more severe acts of partner violence relative to intra-ethnic couples, although Fusco (2010) did not specifically examine partner violence severity.

For this study, we used U.S. general population couples' data for whites, blacks, and Hispanics to examine the association between couples' ethnicity (i.e., interethnic versus intra-ethnic couples) and IPV. Findings from this study will add to what is currently a limited research literature on IPV and interethnic couples. We predicted that interethnic couples would experience higher rates of IPV, particularly mutual partner violence and more severe IPV, compared to white, black, and Hispanic intra-ethnic couples. Based on a homogamy perspective (Zhang \& Van Hook, 2009), partners that are similar on such socially important characteristics as ethnicity, education, religion, or age will have fewer misunderstandings and less conflict between partners and with extended friends and family. Consistent with this, we hypothesized that partners with dissimilar ethnicities would be more likely to report relationship conflicts like IPV than partners sharing the same ethnic background. Interethnic relationships are reported to face challenges related to more complex relationship histories (e.g., prior marriages and prior children), fewer shared values, and less support from family that could lower relationship stability (Hohmann-Marriott \& Amato, 2008). Two ethnicities may have different beliefs about marriage and expectations for men and women; life cycle events (e.g., pregnancy, childbirth, and acquiring a home) can increase stress and conflict between partners by revealing their cultural differences (Rosenblatt, 2009). 
Interethnic couples are also influenced by their larger social context. They often have the added challenge of experiencing the negative reactions to their relationship from others (Foeman \& Nance, 1999). Families of origin may oppose interethnic marriages, and couples may face racism and other forms of bigotry in their community (Rosenblatt, 2009). The social stigma associated with interethnic couples may be greatest for black-white relationships (Yancey, 2007), which were targeted by race-based legal restrictions on marriage in the U.S. until 1967. Comparatively, interethnic white and Hispanic marriages may encounter less social resistance, although few research studies have examined Hispanic intermarriage (Llerena-Quinn \& Bacigalupe, 2009).

For interethnic couples specifically, we sought to identify the factors associated with intimate partner violence. To our knowledge this is the first study to examine drinking and other correlates of IPV among interethnic couples. Interethnic marriage is strongly associated with age; national data shows sharp decreases in rates of interethnic marriage in older compared to younger married adults (Passel et al., 2010). Additionally, younger age is associated with interethnic dating (Yancey, 2002). Since heavy drinking patterns like binge drinking and alcohol problems tend to be more prevalent in younger age groups (Chen, Dufour, \& Yi, 2004; Harford, Grant, Yi, \& Chen, 2005; Muthen \& Muthen, 2000), we expected that these factors would be associated with risk for IPV in interethnic couples. In addition, the increased social isolation (Hibbler \& Shinew, 2002) and psychological distress (Bratter \& Eschbach, 2006) reported by some interethnic couples could indicate an increased risk for problem drinking. We referred to earlier studies with intra-ethnic couples to guide our analysis of variables predicting IPV for interethnic couples. Younger age, alcohol problems, higher impulsivity, and childhood experiences with violence have been previously associated with IPV, including mutual partner violence and IPV severity in intra-ethnic couples based on the dataset analyzed here (Caetano et al., 2005; Cunradi, Caetano, Clark, \& Schafer, 1999; Cunradi, Caetano, \& Schafer, 2002a; Schafer, Caetano, \& Cunradi, 2004). In this study, we expected that IPV among interethnic couples would be associated with similar risk factors as those identified for intra-ethnic couples.

\section{Method}

\section{Sample}

Subjects were partners in couples interviewed for a general population survey on intimate partner violence, i.e., the National Couples Alcohol Survey. In 1995, 1,925 couples were identified from a multistage probability sample of adults 18 years or older from the 48 contiguous states (excluding Alaska and Hawaii). Couples were married or cohabitating for more than 6 months. Black and Hispanic couples were oversampled. Both partners from 1,635 couples ( $85 \%$ of the 1,925 couples) completed the survey. Some couples $(n=36)$ were later excluded, e.g., interviewers reported that the presence of another person influenced responses for one or both partners; couples with excessive missing data were excluded; and homosexual couples were excluded due to small sample size. Couples that included Asian partners or partners from 'other' ethnicities $(n=43)$ were also excluded due to their small sample size in the dataset.

The current study includes $(N=1,556)$ white, black and Hispanic interethnic and intraethnic couples. For intra-ethnic couples $(n=1440)$ both partners self-reported the same ethnic background, i.e., white couples $(n=555)$, black couples $(n=358)$, and Hispanic couples $(n=527)$. Interethnic couples $(n=116)$ included partners of different ethnic backgrounds; they were of black and white $(n=14)$, Hispanic and white $(n=91)$, and black and Hispanic $(n=11)$ ethnic compositions. Interethnic couples were further classified by the ethnicity of the male and female partners in Table 1. Most interethnic couples $(n=66)$ involved relationships between a white female and a black or Hispanic male. Thirty-nine 
couples were relationships between a black or Hispanic female and a white male. Interethnic minority relationships comprised of a black male and a Hispanic female $(n=5)$ or a Hispanic male and a black female $(n=6)$ were relatively few.

\section{Data Collection}

This study was approved by the Committee for the Protection of Human Subjects of the University of Texas Health Science Center at Houston. Before being interviewed, all subjects signed a written informed consent. Face-to-face interviews were conducted in participants' homes by trained surveyors using standardized questionnaires. Members of the couple were interviewed separately.

\section{Measures}

Couples Ethnicity-Couples in which both partners identified themselves as "Black of Hispanic origin (Latino, Mexican, Central or South American, or any other Hispanic origin)" and "White of Hispanic origin (Latino, Mexican, Central or South American, or any other Hispanic origin)" were classified as Hispanic. Couples in which both partners selfidentified as "Black, not of Hispanic origin" were classified as black. Couples with both partners self-identified as "White, not of Hispanic origin" were classified as white. Hispanic, black, and white couples are intra-ethnic couples. Interethnic couples included partners of different ethnic groups. These couples were self-identified as black and white, Hispanic and white, and black and Hispanic.

Intimate Partner Violence (IPV)—Respondents were asked about the occurrence of 11 physically violent behaviors during the past year that they may have perpetrated against their partner or that their partner may have perpetrated against them. These items were part of the Conflicts Tactics Scale (CTS), Form R (Straus, 1990c) and included: threw something; pushed, grabbed or shoved; slapped; kicked, bit or hit; hit or tried to hit with something; beat up; choked; burned or scalded; forced to have sex; threatened with a knife or gun; and had knife or gun used against you/partner. A positive response to 1 or more violent act identified the occurrence of IPV in the past year. An act of violence did not require confirmation by both partners. IPV was coded 1 if at least one partner reported the occurrence of a violent event, and coded 0 if neither partner reported an event. The CTS's measure of partner violence has acceptable to good internal consistency reliability with alpha coefficients ranging from .69 to .88 (Straus, 1990c). This scale shows evidence of construct validity when compared with rates of physical and mental health problems, acts of verbal and physical aggression, and measures of social desirability and affection between partners (Straus, 1990a, 1990b).

We defined the severity of IPV based on the likelihood of the physical act causing injury to the other partner (Straus, 1990c). For this study moderate IPV included: throwing something; pushing, grabbing or shoving; and slapping. Severe IPV included: kicking, biting or hitting; hitting or trying to hit with something; beating up; choking; burning or scalding; forcing to have sex; threatening with a knife or gun; and using a knife or gun.

IPV involves violence perpetrated by the male partner toward the female partner (i.e., maleto-female partner violence; MFPV), and by the female partner toward the male partner (i.e., female-to-male partner violence; FMPV). Mutual partner violence is bidirectional, involving both MFPV and FMPV.

Relationship Characteristics-Couples were characterized by their marital status, length of relationship, whether they had children in the household, age, education, and income. Couples were classified as married (1) or cohabiting/living together (0). The length 
of their relationship was assessed continuously in years, indicating how long the couple had lived with each other. Children in the household was treated as a categorical variable, coded 1 if $\geq 1$ child 17 years of age or younger was reported to live in the household and 0 if no children were reported. The couple's current age represented the averaged age for both partners in years. The couple's years of education represented the mean years of education completed by both partners, with the highest grade in school completed ranging from 0 to $\geq$ 17. Couple's income included 5 categories 1) $\leq \$ 10,000,2) \$ 10,001$ to $\$ 20,000,3) \$ 20,001$ to $\$ 30,000,4) \$ 30,001$ to $\$ 40,000$, and 5) $>\$ 40,000$.

Psychosocial Factors-Drinking related variables included binge drinking and alcohol problems examined separately for male and female partners. Binge drinking was defined by the frequency of consuming five or more drinks (including beer, wine, or liquor) on an occasion in the past year, categorized for this study as 1) one or more times per month, 2) less than once a month, and 3) not in the past year/abstainer. The binge drinking variable combined responses to a series of questions that measured, separately, 'how often' subjects drank 1-2, 3-4, 5-7, 8-11, and 12 or more drinks of any kind of alcoholic beverage in a single day during the last 12 months (i.e., every day or nearly every day; 3-4 times/week; 1-2 times/week; 1-3 times/month; 7-11 times/year; 3-6 times/year; 2 times/year; 1 time/year; and never during the past year). One drink was the equivalent to 12 grams of absolute alcohol or a 4-ounce glass of wine, 1-ounce shot of distilled spirit, and 12-ounce can or bottle of beer.

Alcohol Problems (see Cunradi et al., 1999) indicated whether a respondent experienced drinking-related social consequences or alcohol dependence symptoms during the past year. A 'yes' response to any one of 23 questions denotes the presence of alcohol problems, i.e., no problems (0) and 1 or more problems (1). Drinking-related social consequences were 1) problems with police, 2) accidents, 3) health-related problems, 4) work-related problems, and 5) financial problems. Questions about relationship problems (i.e., with spouse or partner) and arguments or fights related to drinking were excluded because of their common characteristics with IPV. Alcohol dependence symptoms were associated with alcohol addiction and a physical dependence to alcohol, including withdrawal, tolerance, and impaired control. Specific alcohol-related behaviors, experiences, and feelings were assessed (e.g., in the last year: 'I have often taken a drink the first thing when I wake up in the morning'; 'My drinking interfered with my spare time activities or hobbies'; and 'Sometimes I needed a drink so badly that I couldn't think of anything else').

We generated separate variables for male and female partner impulsivity. Each partner responded to three questions (Cherpitel, 1999): 1) I often act on the spur of the moment without stopping to think, 2) You might say I act impulsively, and 3) Many of my actions seem to be hasty. Respondents were asked whether each statement described them, on a four-point scale ranging from 3 to 0 (i.e., quite a lot, some, a little, or not at all). The mean score for these three items represented a respondent's level of impulsivity, with higher scores reflecting higher levels of impulsivity.

Childhood exposure to parental violence combined two survey questions, indicating whether male and female respondents observed 1) their parents/caregivers and/or 2) their parent/ caregiver and a partner being physically violent with one another during their childhood or adolescence. Those who were exposed to parental violence were coded as 1 , and those who were never exposed were coded as 0 .

Respondents were asked whether or not they experienced childhood physical abuse at the hands of their parent or caregiver during their childhood or adolescence. Acts of parental/ caregiver physical violence included being hit with something, beat up, burned or scalded, 
threatened with a knife or gun, and having a knife or gun used on you. Separate variables were created from male and female partners, coded 0 for did not experience childhood physical abuse and 1 for experienced childhood physical abuse.

\section{Data Analysis}

Analyses were conducted using the software package SUDAAN 10.0 (Research Triangle Institute, 2008). Results were based on weighted survey data to reflect the 1995 National Couples Alcohol Survey's multistage stratified probability sampling strategy and to be representative of the U.S. adult population on certain demographics variables, e.g., ethnicity, metropolitan status, and region of the country. Sampling weights adjusted for the oversampling of blacks and Hispanics and for non-response patterns.

In initial analyses, we examined the proportions or mean statistics for our intimate partner violence, relationship, and psychosocial measures across the 4 groups of interethnic and intra-ethnic couples, i.e., interethnic and white, black, and Hispanic intra-ethnic couples. The $\chi^{2}$ test of independence was used to examine couple differences on categorical measures, while the Wald $F$ statistic in univariate linear regression models tested continuous data. We used a probability value of $<.05$ to determine statistically significant findings.

Two multivariate logistic regression models were conducted. Model 1 tested interethnic couples' risk for IPV relative to white, black, and Hispanic intra-ethnic couples after controlling for covariates. Estimates for the effects of couples' ethnicity on IPV (reference: interethnic couples) were adjusted for male binge drinking (reference: not in past year), female binge drinking (reference: not in past year), male alcohol problems (reference: none), and the continuous variables number of years together and couples' mean age. Variables listed in Table 2 were initially tested as potential confounders for the effects of couples' ethnicity on IPV in logistic regression models. Those variables found to change estimates for couples' ethnicity on IPV by $\geq 10 \%$ were entered as covariates into Model 1 (Maldonado \& Greenland, 1993).

Model 2 examined the predictors of IPV for interethnic couples $(n=116)$. Only those variables that predicted interethnic couples' risk for IPV at a probability level of $<.25$ in univariate logistic regressions were considered for inclusion in the multivariate model (Hosmer \& Lemeshow, 2000). These variables were marital status, male alcohol problems, female binge drinking, female alcohol problems, female childhood physical abuse, number of years together, couples' mean age, male impulsivity, and female impulsivity. All variables were entered and re-evaluated in a multivariate model. One-by-one those variables shown to be non-significant $(p<.05)$ and to not make a meaningful contribution in the multivariate model based on a likelihood ratio test were dropped and a new model was refitted. The final Model 2 included marital status (reference: married), male alcohol problems (reference: none), female childhood physical abuse (reference: no abuse), and the continuous variables couples' mean age and female impulsivity.

\section{Results}

\section{Relationship and Psychosocial Characteristics}

A higher percentage of white couples were married compared to interethnic, black, and Hispanic couples (Table 2). The mean age of interethnic couples was younger than other couples, particularly white and black couples. Interethnic couples also had the lowest mean number of years together relative to all intra-ethnic couples. Hispanic couples were most likely to have children (ages 17 or younger) in their household, followed by black, interethnic, and white couples. On average Hispanic couples completed fewer years of education than white, black, and interethnic couples. Hispanic and black couples had lower 
incomes compared to interethnic and white couples; most Hispanic and black couples had yearly incomes less than $\$ 30,000$, while most interethnic and white couples had incomes over $\$ 30,000$ a year.

Drinking variables varied for male partners, but not for female partners across couples' ethnicity. Males in interethnic couples were more frequent binge drinkers, with $42 \%$ binge drinking 1 or more times per month versus $12 \%, 17 \%$, and $26 \%$ of males in white, black, and Hispanic couples, respectively. Similarly, more males in interethnic couples reported alcohol problems than males in intra-ethnic couples. Higher rates of exposure to parental violence were reported by males and females in black and Hispanic couples. Males in black couples were more likely to report childhood physical abuse, with comparatively lower rates for interethnic, white, and Hispanic couples.

\section{Intimate Partner Violence}

The prevalence rate for any occurrence of IPV was highest for interethnic couples, followed by black and Hispanic couples and then white couples (Table 3). Interethnic couples reported the highest prevalence rates relative to other couples for 5 out of the 11 individual acts of violence examined, including 1) threw something, 2) pushed, grabbed or shoved, 3) slapped, 4) kicked, bit or hit, and 5) hit or tried to hit with something. Black and Hispanic couples reported higher rates than interethnic and whites couples for 4 of the remaining 6 acts, i.e., beat up, choked, forced to have sex, and threatened with a knife or gun. Despite black and Hispanic couples' higher rates for these severe acts of partner violence, interethnic couples were more likely to report severe IPV based on their higher rates of kicking, biting or hitting, and hitting or trying to hit with something. Rates of moderate IPV were only somewhat higher in interethnic couples relative to other couples. Among couples that report IPV (Table 4), most occurrences of IPV for interethnic couples were mutual, involving bidirectional male and female perpetrated violence. Black couples reporting IPV also had higher rates of mutual violence, while white and Hispanic couples reported more unidirectional partner violence, i.e., male-to-female (MFPV) and female-to-male (FMPV) perpetrated violence only.

Additionally, for couples reporting mutual violence, one-fourth (25.87\%) of violence perpetrated by the male partner toward the female partner was severe, while half $(49.36 \%)$ of female perpetrated violence was severe. These rates varied by couples ethnicity, with lower rates of severe violence for white couples (male perpetrated: $18.94 \%$; female perpetrated: $41.02 \%$ ) compared to interethnic couples (male perpetrated: $37.65 \%$; female perpetrated: $58.15 \%$ ) and Hispanic (male perpetrated: $37.72 \%$; female perpetrated: $62.62 \%$ ) and black (male perpetrated: $41.78 \%$; female perpetrated: $73.63 \%$ ) couples.

\section{Multivariate Regressions for IPV}

We tested two multivariate logistic regression models predicting any occurrence of IPV in the past year (Table 5). In Model 1, we found no differences in IPV risk for interethnic couples compared to white, black, and Hispanic intra-ethnic couples after controlling for couples' age and years together, male binge drinking, male alcohol problems, and female binge drinking. Among interethnic couples (Model 2), significant predictors of IPV were marital status, couple's mean age, male alcohol problems, and female impulsivity. Couples' older age was protective of IPV, while couples that lived together were at greater risk for IPV compared to married couples. Couples with a male partner that had one or more alcohol problems and a female partner with higher levels of impulsivity were more likely to experience IPV. Couples including a female partner who experienced physical abuse in her childhood also had increased odds for IPV, although confidence intervals included 1.0 (no association). 


\section{Discussion}

Our study helps to fill a gap in the research literature on partner violence by examining the characteristics and correlates of IPV in interethnic couples. We provide further evidence of the high risk for partner violence in interethnic couples. Fusco (2010) identified greater risk for assaults that involved both partners and for victims of IPV to be physically injured in interethnic versus intra-ethnic couples. We showed that past year prevalence rates for any occurrence of IPV and acts of severe IPV were higher for interethnic couples relative to white, black, and Hispanic couples. IPV for interethnic couples was mutual, perpetrated by both partners in the couple. Studies among intra-ethnic couples have previously identified black couples as a particularly high risk group for mutual partner violence and severe IPV (Caetano et al., 2005; Cazenave \& Straus, 1990; Cunradi et al., 2002a). Interethnic couples in this study had higher occurrences of mutual and severe partner violence than black couples, although black couples were more likely to report some of the most severe individual acts of violence (i.e., being beat up, choked, forced to have sex, and threatened with a weapon).

The elevated IPV rates for interethnic couples may be explained by differences between interethnic and intra-ethnic couples in relationship characteristics and drinking related behaviors. Interethnic couples were younger in age than intra-ethnic couples, a factor associated with increased risk for partner violence (Caetano et al., 2005; Cunradi et al., 2002a), and had been living together for fewer years. Other risk factors for IPV, including risky drinking patterns and alcohol problems, were also more prevalent in interethnic compared to intra-ethnic couples. Leadley et al. (2000) previously showed that interethnic couples were three times more likely than intra-ethnic white couples to experience relationship problems related to drinking. In this study, male partners in interethnic couples were more frequent binge drinkers and were more likely to have social problems and alcohol dependence symptoms associated with drinking. Consequently, after controlling for couples' age and length of relationship, male and female binge drinking and male alcohol problems, interethnic and intra-ethnic couples showed similar risks for IPV.

Alcohol has been shown to play a role in partner violence and other types of relationship conflicts (Field \& Caetano, 2004; Leonard \& Eiden, 2007). Cunradi et al. (1999) identified alcohol-related problems rather than the level of alcohol consumption as an important predictor of IPV in white, black, and Hispanic intra-ethnic couples. Similarly, in this study we showed that male alcohol problems predicted increased risk for partner violence in interethnic couples. Couples who were living together versus married were also at greater risk for IPV, while age was protective for IPV in interethnic couples. The inverse effect of age on IPV is a consistent finding in family studies (Suitor, Pillemer, \& Straus, 1990), which show declines in marital violence across the lifespan.

Our finding on female impulsivity also supports existing research on IPV in intra-ethnic couples. We identified a positive relationship between level of female partner impulsivity and IPV in interethnic couples. Female impulsivity in white, black, and Hispanic intra-ethnic couples has been shown to positively affect MFPV and FMPV both directly and indirectly through female alcohol problems (Schafer et al., 2004). Impulsivity can be conceptualized to involve a preference for quick action, carelessness, and disregard for negative consequences, including in response to a distressful situation (Magid, MacLean, \& Colder, 2007). In a sample of women arrested for IPV, impulsivity predicted both psychological and physical violence perpetration for women (Shorey, Brasfield, Febres, \& Stuart, 2011). Impulsivity was associated with trait anger in the sample (i.e., the general tendency to become angry and/or respond to stressful situations with anger), which mediated the relationship between impulsivity and IPV. The tendency toward anger for women with greater impulsivity, as 
well as the positive relationship between impulsivity and alcohol problems, could help explain the association between female impulsivity and IPV. Among interethnic couples, the significant effect of both female and male partner predictors (i.e., male alcohol problems and female impulsivity) on IPV is not unexpected since partner violence for these couples is primarily bidirectional.

The effect of low socioeconomic status (SES) on IPV in intra-ethnic couples has been previously considered. Cunradi et al. (2002b) associated lower income among black and Hispanic couples with MFPV and lower income among black couples with FMPV. Cazenave and Straus (1990) further identified black-white income differences as a contributory factor to black-white differences in family violence. Socioeconomic factors for interethnic couples may have a more limited role in affecting IPV. Intermarriages in the U.S. toward the end of the $20^{\text {th }}$ century shifted from being more concentrated in individuals with lower levels of education to being more concentrated in those with higher levels of education (Fryer, 2007). Interethnic couples in this study fell between white intra-ethnic couples and black and Hispanic intra-ethnic couples on measures of SES; they had slightly lower education and income levels than white couples, but higher levels than black couples and particularly Hispanic couples. Additionally, we found that neither income nor education explained interethnic and intra-ethnic couple differences in IPV and these SES factors did not predict IPV in interethnic couples.

Relationship satisfaction, social support, and experiences of discrimination may be important factors associated with IPV for interethnic couples. However, measures for these factors were not available in the study dataset. Decreased marital satisfaction and increased marital conflict are reliable predictors of physical partner violence (Stith, Green, Smith, \& Ward, 2008). Troy et al. (2006) showed no difference in reported conflict between interethnic and intra-ethnic dating couples. Conversely, Hohmann-Marriott and Amato (2008) identified less relationship satisfaction and more conflict for interethnic couples compared to same-ethnic couples based on a national survey. A lower relationship quality for these interethnic couples was in part attributed to a lack of social support from parents. Among black-white interethnic couples, Killian (2002) documented incidents of rejection and negative attention to their relationship from family and friends as well as in public. The sanctions and stigma faced by black-white couples in the larger social context appear to be higher than those experienced by other interethnic couples (Yancey, 2007). Black-white interethnic couples, in an effort to avoid negative social reactions, report isolating themselves socially from family, work, and leisure activities (Hibbler \& Shinew, 2002). Psychological distress appears high for some but not all partners in interethnic marriages (Bratter \& Eschbach, 2006). In particular, white women married to ethnic minority husbands (i.e., black, Hispanic, Asian, or Native American) and Hispanic men and women married to non-Hispanic, ethnic minority spouses report increased levels of psychological distress compared to respective partners in intra-racial couples.

The National Couples Alcohol Survey is a representative adult sample of married and cohabitating couples drawn from the general U.S. population. This national dataset allows study findings to be generalized to the U.S. population of white, black, and Hispanic interethnic and intra-ethnic couples, although regional differences in interethnic marriages (Fryer, 2007; Passel et al., 2010) may also suggest regional differences in prevalence rates and associated factors for IPV in interethnic couples. The data from this 1995 survey may not be reflective of the current situation given changes in ethnic relations in the U.S. since its collection. This is a limitation of the current study. U.S. rates of interethnic marriages and approval for interethnic couples have continued to increase from 1995 to 2011. Our findings should be re-examined using a more recent sample of interethnic couples. It will be important for future research among interethnic couples to also examine cohort effects on 
partner violence (Suitor et al., 1990). For example, Bratter and King (2008) found higher rates of divorce for interethnic couples marrying during the late-1980s, which may suggest cohort differences in the occurrence of the related behavior IPV (Ramisetty-Mikler \& Caetano, 2005). Study findings may not apply to a more diverse sample of interethnic couples. For example, white-Asian marriages make up a large percentage of interethnic marriages (Hattery, 2009), but we were not able to include them in this study due to the small number of Asians surveyed.

Our findings may have been limited by the relatively small size of the interethnic couple subsample when identifying predictors of IPV in interethnic couples. Confidence intervals for some variables in the regression model predicting IPV among interethnic couples included a wide range of estimates. We were unable to conduct a more focused analysis of IPV by gender and ethnicity or across interethnic couples of different ethnic compositions (i.e., black-white; Hispanic-white; black-Hispanic couples) since the sample sizes for these interethnic couple subgroups were small. Hattery (2009) found different rates of MFPV between male/black-female/white and male/white-female/black interethnic couples. Fusco (2010) found that more police-reported IPV events involved a black perpetrator and white victim compared to interethnic couples of other ethnic compositions; most police-reported mutual partner violence events occurred between a black male and a white female.

The CTS Form R, used to measure IPV in this study, has not been extensively validated in ethnic minority samples and is limited in its ability to capture the complexities of mutual partner violence. Among mutually violent couples, higher rates of severe female perpetrated violence were reported compared to severe male perpetrated violence. However, the CTS does not distinguish whether mutual violence involved a primary aggressor and self defending victim or two mutually combative partners or determine the impact of the violence perpetrated. Weston et al. (2005) using a community sample, found that mutually violent relationships were predominantly characterized by a male primary perpetrator (MPP) versus a female primary perpetrator or symmetrical violence, and that women in MPP relationships were more likely to be injured than their male partners.

In conclusion, this study suggests that interethnic couples are at increased risk for IPV compared intra-ethnic couples based on national population data. Interethnic couples showed higher prevalence rates than intra-ethnic couples for any occurrence of IPV and severe partner violence. Most occurrences of IPV for interethnic couples were bidirectional. Both female and male risk factors (i.e., male alcohol problems and female impulsivity) predicted IPV for these couples. Higher rates of IPV for interethnic couples may be attributed to differences between interethnic and intra-ethnic couples in couples' age, binge drinking, and male alcohol problems. To build on this study, future research with interethnic couples could examine cohort effects and regional differences in IPV and test relationship conflict and social support as predictors of IPV. A more detailed analysis of IPV across interethnic couples of different ethnic compositions may help specify those interethnic couples that are most at risk for partner violence.

\section{Acknowledgments}

We would like to thank Kierste Miller for her help in preparing this paper. This work was supported by the National Institute on Alcohol Abuse and Alcoholism Grant No. R37 AA10908.

\section{Biography}

Karen G. Chartier, Ph.D., M.S.W., is a Faculty Associate at the University of Texas School of Public Health, Dallas regional campus. She completed her post-doctoral training in alcohol research at University of Connecticut School of Medicine, where she studied 
problem alcohol use during adolescence and early adulthood. Her research interests include ethnic group differences in drinking, alcohol problems, and alcohol treatment utilization. She earned her Ph.D. and M.S.W. from the University of Connecticut School of Social Work.

Raul Caetano, M.D., M.P.H., Ph.D. is Dean and Professor of Health Care Sciences and Psychiatry, Southwestern School of Health Professions, University of Texas Southwestern Medical Center, and Regional Dean and Professor of Epidemiology, University of Texas School of Public Health. His research has focused on the epidemiology of alcohol consumption, drinking problems and domestic violence among U.S. ethnic minorities, especially Hispanics. Another area of research is the epidemiology of alcohol dependence and the development of diagnostic criteria for alcohol dependence.

\section{References}

Bratter JL, Eschbach K. 'What about the couple?' Interracial marriage and psychological distress. Social Science Research. 2006; 35(4):1025-1047.

Bratter JL, King RB. “But Will It Last?”: Marital instability among interracial and same-race couples. Family Relations. 2008; 57(2):160-171.

Caetano R, Cunradi CB, Clark CL, Schafer J. Intimate partner violence and drinking patterns among white, black, and Hispanic couples in the US. Journal of Substance Abuse. 2000; 11(2):123-138. [PubMed: 10989773]

Caetano R, Ramisetty-Mikler S, Field CA. Unidirectional and bidirectional intimate partner violence among White, Black, and Hispanic couples in the United States. Violence Victims. 2005; 20(4): 393-406.

Carroll, J. Most Americans Approve of Interracial Marriages. Gallup, Inc.; Princeton, NJ: 2007.

Cazenave, NA.; Straus, MA. Race, class, network embeddedness and family violence: A search for potent support systems.. In: Straus, MA.; Gelles, RJ., editors. Physical Violence in American Families: Risk Factors and Adaptations in Violence in 8,145 Families. Transactions Books; New Brunswick, NJ: 1990. p. 321-339.

Chen CM, Dufour MC, Yi H. Alcohol consumption among young adults ages 18-24 in the United States: Results from the 2001-2002 NESARC survey. Alcohol Research and Health. 2004; 28(4): 269-280.

Cherpitel CJ. Substance Use, Injury, and Risk-Taking Dispositions in the General Population. Alcoholism: Clinical and Experimental Research. 1999; 23(1):121-126.

Cunradi CB, Caetano R, Clark CL, Schafer J. Alcohol-related problems and intimate partner violence among white, black and Hispanic couples in the US. Alcoholism: Clinical and Experimental Research. 1999; 23(9):1492-1501.

Cunradi CB, Caetano R, Schafer J. Alcohol-related problems, drug use, and male intimate partner violence severity among US couples. Alcoholism: Clinical and Experimental Research. 2002a; 26(4):493-500.

Cunradi CB, Caetano R, Schafer J. Socioeconomic predictors of intimate partner violence among White, Black, and Hispanic couples in the United States. Journal of Family Violence. 2002b; 17(4):377-389.

Field CA, Caetano R. Ethnic differences in intimate partner violence in the U.S. general population: The role of alcohol use and socioeconomic status. Trauma Violence \& Abuse. 2004; 5(4):303317.

Foeman AK, Nance T. From Miscegenation to Multiculturalism: Perceptions and Stages of Interracial Relationship Development. Journal of Black Studies. 1999; 29(4):540-557.

Fryer RG. Guess who's been coming to dinner? Trends in interracial marriage over the 20th century. Journal of Economic Perspectives. 2007; 21(2):71-90.

Fusco RA. Intimate Partner Violence in Interracial Couples: A Comparison to White and Ethnic Minority Monoracial Couples. Journal of Interpersonal Violence. 2010; 25(10):1785-1800. [PubMed: 19966246] 
Harford TC, Grant BF, Yi HY, Chen CM. Patterns of DSM-IV alcohol abuse and dependence criteria among adolescents and adults: results from the 2001 National Household Survey on Drug Abuse. Alcoholism: Clinical and Experimental Research. 2005; 29(5):810-828.

Hattery, AJ. Intimate Partner Violence. Rowman \& Littlefield Publishers, Inc.; Lanham, MD: 2009.

Hibbler DK, Shinew KJ. Interracial couples' experience of leisure: A social network approach. Journal of Leisure Research. 2002; 34(2):135-156.

Hohmann-Marriott BE, Amato P. Relationship Quality in Interethnic Marriages and Cohabitations. Social Forces. 2008; 87(2):825-855.

Hosmer, DW.; Lemeshow, S. Applied Logistic Regression. 2nd ed.. John Wiley \& Sons; New York: 2000.

Killian KD. Dominant and Marginalized Discourses in Interracial Couples' Narratives: Implications for Family Therapists. Family Process. 2002; 41(4):603-618. [PubMed: 12613119]

Leadley K, Clark CL, Caetano R. Couples' drinking patterns, intimate partner violence, and alcoholrelated partnership problems. Journal of Substance Abuse. 2000; 11(3):253-263. [PubMed: 11026124]

Leonard KE, Eiden RD. Marital and family processes in the context of alcohol use and alcohol disorders. Annual Review of Clinical Psychology. 2007; 3:285-310.

Llerena-Quinn, R.; Bacigalupe, G. Constructions of Difference among Latino and Latina Immigrants and Non-Hispanic White Couples.. In: Harris, T.; Killian, K., editors. Intercultural Couples: Exploring Diversity in Intimate Relationships. Taylor and Francis Group; New York: 2009. p. 167-185.

Magid V, MacLean MG, Colder CR. Differentiating between sensation seeking and impulsivity through their mediated relations with alcohol use and problems. Addictive Behaviors. 2007; 32(10):2046-2061. [PubMed: 17331658]

Maldonado G, Greenland S. Simulation study of confounder-selection strategies. American Journal of Epidemiology. 1993; 138(11):923-936. [PubMed: 8256780]

Mercy JA, Saltzman LE. Fatal violence among spouses in the United States, 1976-85. American Journal of Public Health. 1989; 79(5):595-599. [PubMed: 2705594]

Muthen BO, Muthen LK. The development of heavy drinking and alcohol-related problems from ages 18 to 37 in a U.S. national sample. Journal of Studies on Alcohol. 2000; 61(2):290-300. [PubMed: 10757140]

Passel, JS.; Wang, W.; Taylor, P. [November 12, 2010] Marrying out: One-in-seven marriages is interracial or interethnic. 2010. from http://pewsocialtrends.org/

Ramisetty-Mikler S, Caetano R. Alcohol use and intimate partner violence as predictors of separation among U.S. couples: a longitudinal model. Journal of Studies on Alcohol. 2005; 66(2):205-212. [PubMed: 15957671]

Research Triangle Institute. SUDAAN (Version 10.0). RTI International; Research Triangle Park, NC: 2008.

Rosenblatt, PC. A systems theory analysis of intercultural couple relationships. In (Eds.), Intercultural couples: Exploring diversity in intimate relationships (pp. 3-20).. In: Karis, TA.; Killian, KD., editors. Intercultural Couples: Exploring Diversity in Intimate Relationships. Routledge; Taylor and Francis Group; New York: New York: 2009. p. 3-20.

Schafer J, Caetano R, Cunradi CB. A path model of risk factors for intimate partner violence among couples in the United States. Journal of Interpersonal Violence. 2004; 19(2):127-142. [PubMed: 15005998]

Shorey RC, Brasfield H, Febres J, Stuart GL. The association between impulsivity, trait anger, and the perpetration of intimate partner and general violence among women arrested for domestic violence. Journal of Interpersonal Violence. 2011; 26(13):2681-2697. [PubMed: 21118862]

Stith SM, Green NM, Smith DB, Ward DB. Marital satisfaction and marital discord as risk markers for intimate partner violence: A meta-analytic review. Journal of Family Violence. 2008; 23(3):149160.

Straus, MA. The conflict tactics scales and its critics: An evaluation and new data on validity and reliability.. In: Straus, MA.; Gelles, RJ., editors. Physical violence in American families: Risk 
factors and adaptations to violence in 8,145 families. Transaction Publishers; New Brunswick, NJ: 1990a. p. 49-73.

Straus, MA. Measuring intrafamily conflict and violence: the conflict tactics (CT) scales.. In: Straus, MA.; Gelles, RJ., editors. Physical violence in American families: Risk factors and adaptations to violence in 8,145 families. Transaction Publishers; New Brunswick, NJ: 1990b. p. 29-47.

Straus, MA. New Scoring Methods for Violence and New Norms for the Conflict Tactics Scales.. In: Straus, MA.; Gelles, RJ., editors. Physical violence in American families: Risk factors and adaptations to violence in 8,145 families. Transaction Publishers; New Brunswick, NJ: 1990c. p. 535-559.

Straus, MA.; Smith, C. Violence in Hispanic families in the United States: Incidence rates and structural interpretations.. In: Straus, MA.; Gelles, RJ., editors. Physical Violence in American Families: Risk Factors and Adaptations in Violence in 8,145 Families. Transactions Books; New Brunswick, NJ: 1990. p. 341-363.

Suitor, JJ.; Pillemer, K.; Straus, MA. Marital Violence in a Life Course Perspective.. In: Straus, MA.; Gelles, RJ., editors. Physical Violence in American Families: Risk Factors and Adaptations in Violence in 8,145 Families. Transactions Books; New Brunswick, NJ: 1990. p. 305-317.

Troy AB, Lewis-Smith J, Laurenceau J. Interracial and intraracial romantic relationships: The search for differences in satisfaction, conflict, and attachment style. Journal of Social and Personal Relationships. 2006; 23(1):65-80.

Weston R, Temple J, Marshall L. Gender Symmetry and Asymmetry in Violent Relationships: Patterns of Mutuality Among Racially Diverse Women. Sex Roles. 2005; 53(7):553-571.

Yancey G. Who interracially dates: An examination of the characteristics of those who have interracially dated. Journal of Comparative Family Studies. 2002; 33(2):179-190.

Yancey G. Experiencing racism: Differences in the experiences of Whites married to Blacks and nonBlack racial minorities. Journal of Comparative Family Studies. 2007; 38(2):197-213.

Zhang Y, Van Hook J. Marital Dissolution Among Interracial Couples. Journal of Marriage and Family. 2009; 71(1):95-107. 


\section{Table 1}

Interethnic Couples $(N=116)$ by the Ethnicity of Male and Female Partners

\begin{tabular}{lccc}
\hline & \multicolumn{3}{c}{ Male partners } \\
\cline { 2 - 4 } Female partners & White & Black & Hispanic \\
\hline White & -- & 10 & 56 \\
Black & 4 & -- & 6 \\
Hispanic & 35 & 5 & -- \\
\hline
\end{tabular}

Note: Numbers are $n$ 's for each interethnic couple subgroup. 
Table 2

Relationship and Psychosocial Characteristics for U.S. Interethnic and Intra-ethnic Couples

\begin{tabular}{|c|c|c|c|c|}
\hline & \multirow[b]{2}{*}{ Interethnic couples $(n=116)$} & \multicolumn{3}{|c|}{ Intra-ethnic couples } \\
\hline & & $\begin{array}{l}\text { White couples } \\
\quad(n=555)\end{array}$ & $\begin{array}{l}\text { Black couples } \\
\quad(n=358)\end{array}$ & $\begin{array}{l}\text { Hispanic couples } \\
\quad(n=527)\end{array}$ \\
\hline \multicolumn{5}{|l|}{$\underline{\text { Couples }}$} \\
\hline Married $^{* *}$ & $82.50(5.07)$ & $91.56(1.03)$ & $82.61(2.38)$ & $84.15(3.03)$ \\
\hline Mean Age ${ }^{* * *}$ & $37.76(1.80)$ & $47.79(0.82)$ & $43.14(0.78)$ & $40.02(1.10)$ \\
\hline Years together (mean) ${ }^{* * *}$ & $10.14(1.47)$ & $21.13(0.92)$ & $15.80(0.85)$ & $15.21(1.32)$ \\
\hline Children in $\mathrm{HH}^{* * *}$ & $54.29(7.43)$ & $44.30(2.62)$ & $60.35(2.86)$ & $67.95(2.79)$ \\
\hline Mean education ${ }^{* * *}$ & $12.87(0.30)$ & $13.03(0.16)$ & $12.30(0.17)$ & $9.81(0.34)$ \\
\hline \multicolumn{5}{|l|}{ Income $e^{* * *}$} \\
\hline$\leq \$ 10,000$ & $5.47(2.15)$ & $5.07(0.87)$ & $26.13(2.87)$ & $25.06(3.25)$ \\
\hline$\$ 10,001-20,000$ & $17.36(5.22)$ & $11.94(1.32)$ & $13.19(1.65)$ & $29.41(2.39)$ \\
\hline$\$ 20,001-30,000$ & $14.76(3.42)$ & $16.34(1.83)$ & $16.70(2.25)$ & $21.36(2.87)$ \\
\hline$\$ 30,001-40,000$ & $20.01(5.81)$ & $14.69(1.58)$ & $16.23(1.97)$ & $9.85(1.52)$ \\
\hline$>\$ 40,001$ & $42.40(7.44)$ & $51.95(2.23)$ & $27.75(3.07)$ & $14.32(1.91)$ \\
\hline \multicolumn{5}{|l|}{ Male partners } \\
\hline \multicolumn{5}{|l|}{ Binge drinking ${ }^{* * *}$} \\
\hline $1+$ times/month & $42.12(7.06)$ & $11.69(1.57)$ & $16.96(2.63)$ & $26.21(1.97)$ \\
\hline$<$ Once a month & $18.30(3.67)$ & $25.15(2.01)$ & $15.26(2.42)$ & $17.84(2.51)$ \\
\hline Not in past year & $39.59(6.38)$ & $63.17(2.27)$ & $67.78(2.77)$ & $55.95(2.57)$ \\
\hline Alcohol problems ${ }^{* * *}$ & $29.59(6.41)$ & $9.14(1.34)$ & $17.57(2.27)$ & $20.13(2.00)$ \\
\hline Mean impulsivity & $1.00(0.11)$ & $0.78(0.04)$ & $0.73(0.05)$ & $0.77(0.04)$ \\
\hline Childhood exposure to parental violence ${ }^{* * *}$ & $21.65(5.17)$ & $15.75(1.81)$ & $27.41(2.69)$ & $28.57(3.26)$ \\
\hline Childhood physical abuse ${ }^{* * *}$ & $60.70(7.19)$ & $64.79(2.56)$ & $77.49(2.61)$ & $64.15(2.12)$ \\
\hline \multicolumn{5}{|l|}{ Female partners } \\
\hline \multicolumn{5}{|l|}{ Binge drinking } \\
\hline $1+$ times/month & $6.77(3.84)$ & $3.01(0.70)$ & $4.22(1.04)$ & $3.70(1.41)$ \\
\hline$<$ Once a month & $22.84(5.66)$ & $12.46(1.80)$ & $9.50(1.96)$ & $8.05(1.39)$ \\
\hline Not in past year & $70.39(6.25)$ & $84.53(1.92)$ & $86.28(1.95)$ & $88.25(2.44)$ \\
\hline Alcohol problems & $9.44(4.05)$ & $6.99(1.20)$ & $8.19(1.64)$ & $5.05(1.89)$ \\
\hline Mean impulsivity & $0.90(0.08)$ & $0.78(0.04)$ & $0.78(0.04)$ & $0.75(0.05)$ \\
\hline Childhood exposure to parental violence ${ }^{*}$ & $19.40(4.77)$ & $17.74(1.73)$ & $23.66(2.79)$ & $25.82(2.50)$ \\
\hline Childhood physical abuse & $50.70(6.95)$ & $49.40(2.33)$ & $59.11(3.47)$ & 52.57 (3.64) \\
\hline
\end{tabular}

Notes: Estimates are percent or mean (standard error); Interethnic couples include black-white, Hispanic-white, and black-Hispanic couples; Children in $\mathrm{HH}=$ children $\leq 17$ years of age living in household

*

$p<.05$

** $p<.01$

J Interpers Violence. Author manuscript; available in PMC 2012 June 01. 
**** $p<.001$. 
Table 3

Intimate Partner Violence (IPV) for U.S. Interethnic and Intra-ethnic Couples

\begin{tabular}{|c|c|c|c|c|}
\hline & \multirow{2}{*}{$\begin{array}{c}\text { Interethnic couples }(n= \\
116)\end{array}$} & \multicolumn{3}{|c|}{ Intra-ethnic couples } \\
\hline & & White couples $(n=555)$ & Black couples $(n=358)$ & $\begin{array}{l}\text { Hispanic couples }(n= \\
\text { 527) }\end{array}$ \\
\hline Any IPV ${ }^{* * * *}$ & $39.19(6.40)$ & $18.56(2.00)$ & $33.14(3.78)$ & $26.33(2.36)$ \\
\hline Throw something ${ }^{* *}$ & $24.55(5.39)$ & $10.86(1.47)$ & $22.71(3.09)$ & $14.84(2.29)$ \\
\hline Push, shove, grab ${ }^{* *}$ & $33.35(6.23)$ & $13.57(1.70)$ & $27.51(3.80)$ & $17.77(2.16)$ \\
\hline Slap $^{* *}$ & $15.52(4.72)$ & $4.98(1.03)$ & $13.52(2.95)$ & $10.13(1.95)$ \\
\hline Kick, bite, hit ${ }^{*}$ & $11.49(4.38)$ & $3.09(0.87)$ & $10.09(2.85)$ & $6.79(1.05)$ \\
\hline Hit with something ${ }^{* * *}$ & $20.61(5.66)$ & $4.17(0.94)$ & $16.52(2.95)$ & $10.08(1.26)$ \\
\hline Beat up ${ }^{*}$ & $1.67(1.31)$ & $0.31(0.22)$ & $2.98(1.04)$ & $3.45(1.01)$ \\
\hline Choke $e^{* * *}$ & $2.25(1.74)$ & $0.44(0.28)$ & $3.68(1.18)$ & $2.60(0.82)$ \\
\hline Burn & $0.00(0.00)$ & $0.38(0.28)$ & $1.38(0.87)$ & $0.21(0.18)$ \\
\hline Force $\operatorname{sex}{ }^{* *}$ & $2.25(1.75)$ & $0.55(0.31)$ & $3.79(1.11)$ & $2.75(0.83)$ \\
\hline Threaten knife/gun ${ }^{*}$ & $0.56(0.46)$ & $0.35(0.21)$ & $3.24(1.07)$ & $1.46(0.50)$ \\
\hline Use knife/gun & $0.43(0.44)$ & $0.29(0.20)$ & $0.86(0.43)$ & $0.89(0.39)$ \\
\hline \multicolumn{5}{|l|}{ Severity of violence ${ }^{* * *}$} \\
\hline Moderate & $14.50(5.54)$ & $13.06(1.65)$ & $13.15(2.16)$ & $12.92(1.64)$ \\
\hline Severe & $25.02(5.41)$ & $5.49(1.16)$ & $20.52(3.01)$ & $13.46(1.62)$ \\
\hline No IPV & $60.47(6.38)$ & $81.44(2.00)$ & $66.34(3.90)$ & $73.62(2.37)$ \\
\hline
\end{tabular}

Notes: Estimates are percent (standard error)

*

$p<.05$

** $p<0$

$* * *$

$p<.001$. 
Table 4

Proportion of Mutual and Unidirectional (MFPV, FMPV) Partner Violence by Couples Ethnicity

\begin{tabular}{lcccc}
\hline & Interethnic couples $(\boldsymbol{n}=\mathbf{4 5})$ & \multicolumn{3}{c}{ Intra-ethnic couples } \\
\cline { 3 - 5 } & & White couples $(\boldsymbol{n}=\mathbf{1 0 8})$ & Black couples $(\boldsymbol{n}=\mathbf{1 2 5})$ & Hispanic couples $(\boldsymbol{n}=\mathbf{1 4 8})$ \\
\hline $\begin{array}{l}\text { Perpetrator } \\
\text { Mutual }\end{array}$ & $71.78(8.02)$ & & & $45.16(5.44)$ \\
MFPV only & $8.75(4.75)$ & $16.57(5.19)$ & $61.14(4.82)$ & $19.38(4.27)$ \\
FMPV only & $19.47(6.86)$ & $38.48(5.08)$ & $8.08(2.74)$ & $35.46(4.08)$ \\
\hline
\end{tabular}

Notes: Estimates are percent (standard error); MFPV = male-to-female partner violence; FMPV = female-to-male partner violence ${ }^{*} p<.05$. 
Table 5

Regressions for IPV in Interethnic and Intra-ethnic Couples and Interethnic Couples Only

\begin{tabular}{|c|c|c|}
\hline & $\begin{array}{c}\text { Model 1 } \\
\text { Full Sample }(N=1,417) \\
\text { OR }(95 \% \text { CI })\end{array}$ & $\begin{array}{c}\text { Model 2 } \\
\text { Interethnic Couples }(N=114) \\
\text { OR }(95 \% \mathrm{CI})\end{array}$ \\
\hline \multicolumn{3}{|l|}{ Couples' ethnicity (ref. Interethnic couples) } \\
\hline White couples & $0.68(0.39,1.17)$ & --- \\
\hline Black couples & $1.30(0.69,2.46)$ & --- \\
\hline Hispanic couples & $0.76(0.44,1.31)$ & --- \\
\hline Married (ref. Yes) & --- & $7.14(1.72,29.60)^{* *}$ \\
\hline Years together & $1.00(0.97,1.03)$ & --- \\
\hline Couples' mean age & $0.95(0.93,0.98)^{* * *}$ & $0.91(0.86,0.97)^{* *}$ \\
\hline \multicolumn{3}{|l|}{ Male binge drinking (ref. Not in past year) } \\
\hline $1+$ times/month & $1.53(0.79,2.94)$ & --- \\
\hline$<$ Once a month & $1.04(0.57,1.88)$ & --- \\
\hline Male alcohol problems (ref. None) & $1.63(0.82,3.23)$ & $9.89(1.89,51.67)^{* *}$ \\
\hline \multicolumn{3}{|l|}{ Female binge drinking (ref. Not in past year) } \\
\hline $1+$ times/month & $2.33(.091,5.94)$ & --- \\
\hline$<$ Once a month & $2.22(1.36,3.61)^{* *}$ & --- \\
\hline Female impulsivity & --- & $4.11(1.49,11.35)^{* *}$ \\
\hline Female childhood physical abuse (ref. No abuse) & --- & $2.57(0.81,8.11)$ \\
\hline
\end{tabular}

Notes: OR is odds ratio; $\mathrm{CI}$ is confidence interval; Model 1 tested interethnic couples' risk for IPV relative to intra-ethnic couples controlling for covariates; Model 2 examined the predictors of IPV for interethnic couples only

**

$p<.01$

*** $p<.001$. 